\title{
A Participatory Decision Support System towards the Transformation of Areas under Disaster Risk
}

\author{
Ahmet Gün and Yüksel Demir
}

\begin{abstract}
Urban interventions, which are both at urban scale and building scale, have been realized only by considering physical values which based on fast construction since the beginning of the $20^{\text {th }}$ century. Residents who are the main actors on urban areas have the right only to use their living areas like any object. They haven't any right to participate in decision-making, design and production of their living areas which generate relations between humans and environment. Moreover, the studies about environmental behavior research show us that personality characteristics and built environment affect and shape each other.

According to Ministry of Environment and Urbanisation announcement (2012), nearly 6,5 million housing unit will be transformed within the scope of "Law no. 6306 on Transformation of Areas under Disaster Risk" next 15-20 years in Turkey. A few urban transformation projects have been realized by considering public participation for the beginning of this process. Most of these interventions have been like West Europe's social housing approach which occurred after the Second World War. One of the reasons of failure about public participation is coordination and communication problem between users and other actors who have the right to take a decision on these interventions. On the other hand, many tools have been developed in other sectors in order to solve these problems by making use of information technologies up to now. Thus, actors which carry on business in different areas can coordinate and take decisions. Decision support systems, which are generally used by operational business and health sector, have important potentials on urban transformation process in Turkey.

This paper is prepared within the scope of "Special Topics in E-motive Architecture" $\mathrm{PhD}$ course which is instructed by Dr. Yuksel Demir at Istanbul Technical University. This study aims to develop a participatory decision support system towards the transformation of areas under disaster risk in Turkey. Thus, firstly, components of decision support system are determined. Then, an integrated model which based on data oriented decision support system is generated in order to provide efficient coordination process amongst these components. At the end of a study, proposed decision support system is evaluated and some suggestions are given towards future studies.
\end{abstract}

Keywords-Decision support systems; public participation; Turkey; urban transformation.

\footnotetext{
First author

${ }^{1}$ Department of Architecture, Istanbul Technical University, 34437, Istanbul, Turkey.

Second author

${ }^{2}$ Department of Architecture, Istanbul Technical University, 34437, Istanbul, Turkey.
}

\section{INTRODUCTION}

Most of the people live in very crowded areas and they accommodate in buildings which are very weak in terms of physical conditions. Moreover, people lose social and cultural values of their living environment because of faulty urban transformation policies. Urban interventions have generally been realized by considering only physical values since the beginning of $20^{\text {th }}$ century. People have only right to use their living areas like any object and they haven't any right to participate in decision-making, design and production of their living areas which generate relations between humans and environment.

These negative developments about urban areas have been observed in Turkey for many years. Many residents have to migrate from their living environment due to the urban transformation process in Turkey. Ministry of Environment and Urbanisation announcement announced in 2012 that nearly 6,5 million housing unit will be transformed within the scope of "Law no. 6306 on Transformation of Areas under Disaster Risk" next 15-20 years in Turkey. Moreover, a revision goes in effect in 2016 so the scope of this law is enlarged. According to author's estimation, nearly $\% 40$ percent of Turkish population will affect directly from this transformation process in next 15-20 years.

When this law is examined, it can be seen that the transformation process is realized by considering only three phases which are determination - evacuation\&pulldown construction. There are not any participatory or flexible approach for residents except for deciding whether their parcels integrated or separated after the evacuation and pulling down phase (Figure 1). 


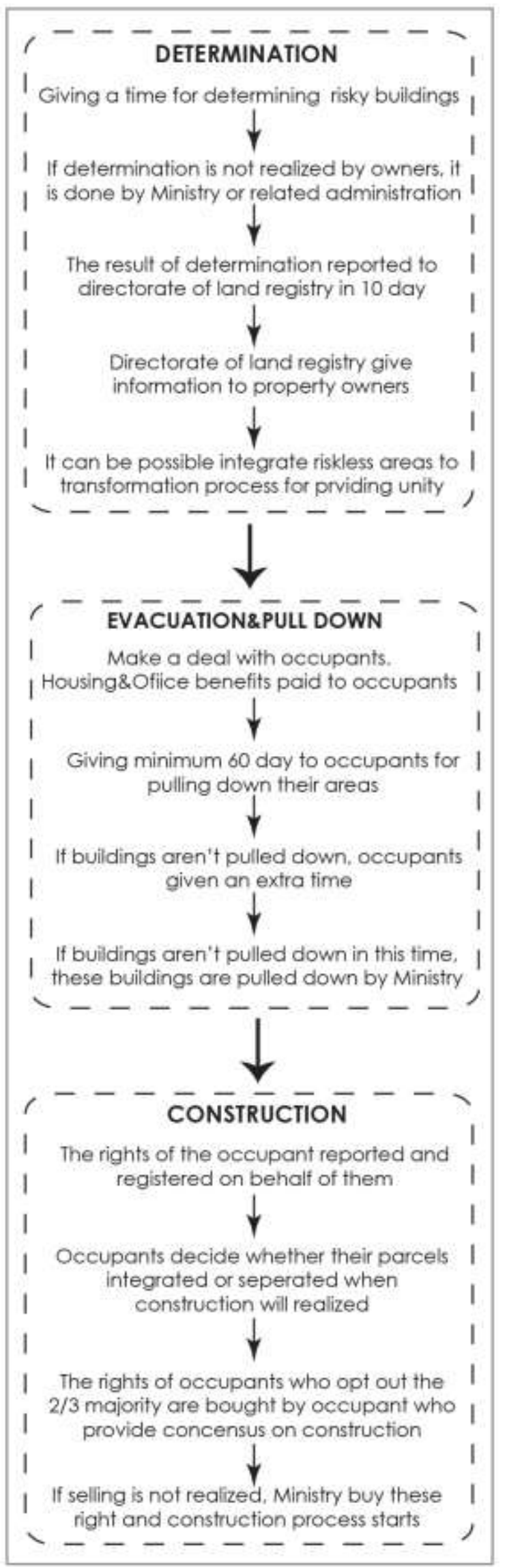

Fig. 1: General structure of Law no. 6306 on Transformation of Areas under Disaster Risk [1]
There is need for developing alternative strategies which include participatory policies, consider local values at neighborhood scale and put humans and human needs to the center of the transformation process. There are a lot of studies have been done about public participation towards to urban interventions such as urban regeneration and urban transformation in developed countries. The transformation process of Mariahilfer Street can be given as an example on this issue. Mariahilfer Street, which was the biggest shopping street a short time ago, was frequently used by cars and the other motor vehicles. After the city council election, the reconstruction process of the street started with stakeholder involvement events which include more than 600 participants that give more than 1.000 ideas for this process. Moreover, physical meetings and online dialog with more than 900 posts were moderated. Selected experts involved process in 2012 and the extra survey was conducted and further stakeholder involvement was realized to collaboratively design the street with citizens, experts and urban planners and then first pilot study was implemented and tested in 2013 (Figure 2-3). The feedback influenced on project for the following phases [2]
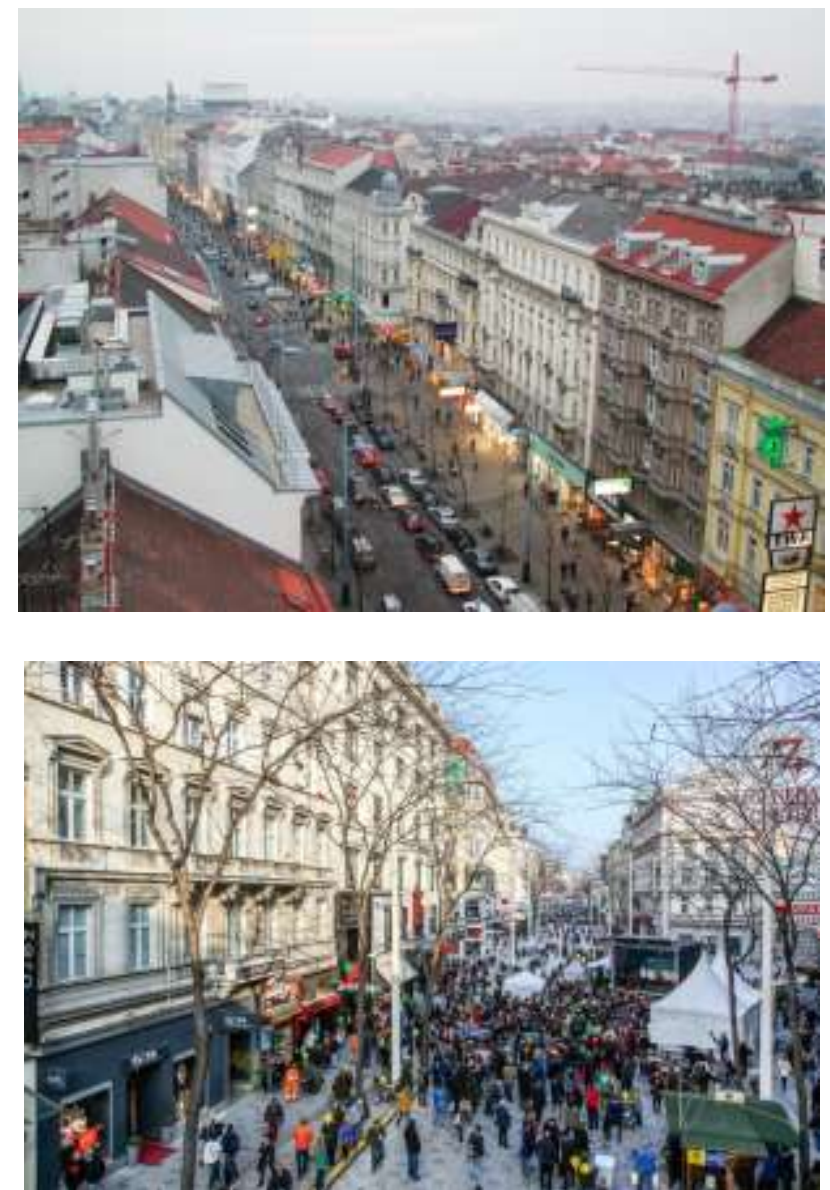

Fig. 2-3: The condition of Mariahilfer street, first figure: before transformation; second figure: after transformation [3] [4].

This study aims to develop a participatory decision support system towards the transformation of areas under disaster risk in Turkey. Thus, proposed decision support system for these areas is explained in next part of the study. 


\section{DECISION SUPPORT SYSTEM FOR TRANSFORMATION OF AREAS UNDER DISASTER RISK}

Urban transformation process includes many actors such as local government members, Ministry's members, residents, NGOs, design and technical team, construction firms etc. so there is need for effective organization and communication atmosphere so that these actors can coordinate and work in a planned way. Thus, important actions such as data collection and share, data visualization, process management, communication amongst actors can be realized by developing a tool in accordance with information technologies. Accordingly, data based decision support system is developed in order to form an atmosphere which provides information flow and communication amongst actors.

Human intuitive judgment and decision making can be far from optimal and it makes worsen with complexity and stress. Aiding to deficiencies of human decision making has been an important focus point of science because the quality of decisions are important. Some disciplines such as economics and statistics aim to develop different methods in order to make rational choices. These methods have been developed by a variety of disciplines such as information science, cognitive psychology and artificial intelligence which have been implemented in the form computer programs in order to make complex decisions. These environments are often termed as a decision support systems [5] (Druzdzel, 1999).

Decision Support Systems (DSS) are computer-based systems which aim to help people to select one choice from the alternative solutions when they confront a problem. DSSs can analyze huge amount of information and it can be helpful for reducing cost, increasing profit and enhancing quality. In brief, it can be defined as an interactive computer-based information system with organized collection of elements such as models, people, software, databases, telecommunication and devices which aid decision makers to solve problems [6]

DSSs are generally used for strategic decisions encountered by upper-level management decisions with high potential consequences| and they are gaining importance in some domains such as business, engineering, military and medicine [5] More recently, DSSs have been used in spatial disciplines such as urban planning and it named as a Spatial Decision Support Systems (SDSS). SDSSs integrate a geographical information systems (GIS) with computer-based modules such as spatial analysis, map analysis and display modules. These systems employ personal in the manner that set planning scenarios can be determined, analyzed and adopted in line with disciplines' standard. These systems are desirable for professional planners, politicians and decision makers when they are required to take decisions [7].

Any effective study has not been done about urban transformation process by means of decision support systems in Turkey until now. Accordingly, there is a need for making studies on this issue which may change the architectural and urban character of Turkish cities and may affect the life of millions of people in next 15-20 years. Thus, the integrated model draft is generated by making use of decision support system and process chart is formed in order to run this model (Figure 4).

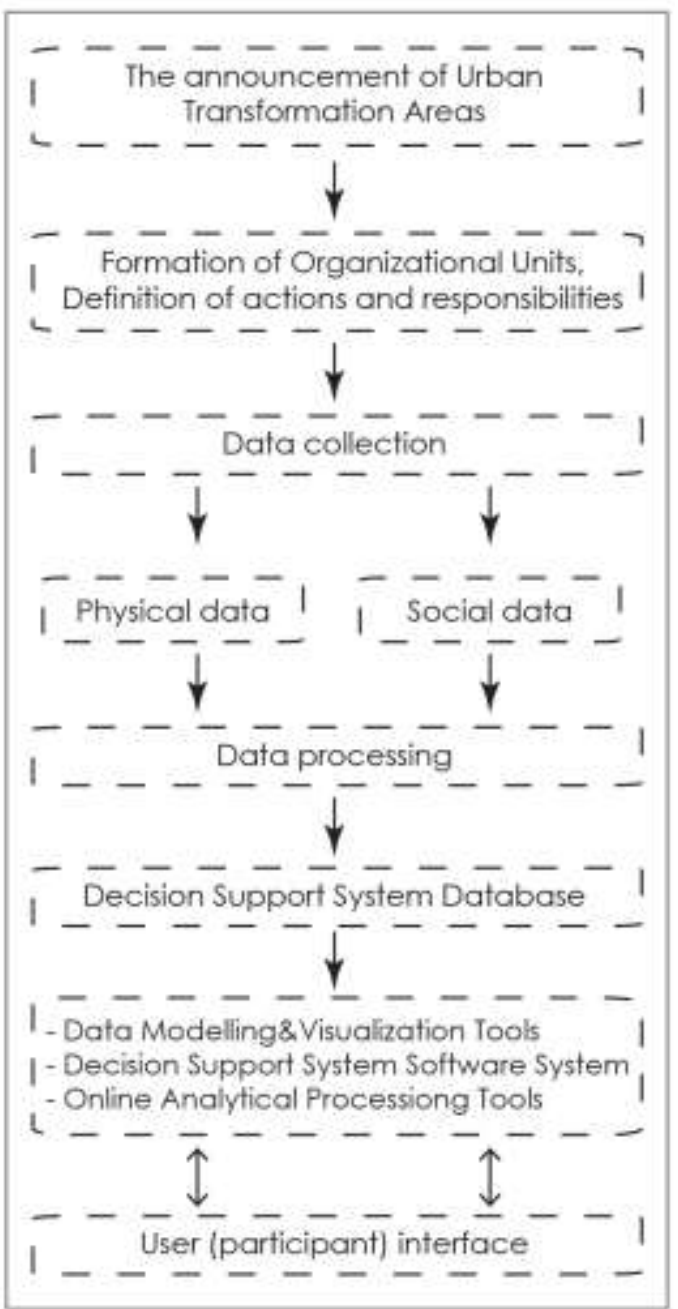

Fig. 4: Process chart towards to transformation of areas under disaster risk

After describing of process chart towards to transformation of areas under disaster risk, it is aimed to develop decision support system for these areas. Thus, a data-based decision support system, which analyzes data repository and exists within the structure of big organizational systems, is decided to use in this process. The components of the system are explained below:

- Urban Transformation Area Announcement Platform: The announcements of urban transformation areas are maken only to owners instead of announcing to all community explicitly. These areas are important not only for people who live or work in these areas but also they are important for all citizens in terms of collective memory. Thus, urban transformation areas should be announced and community should be informed democratically via tools such as social media applications, internet portals etc. There are some internet platforms serve for this purpose like Buerger baut Stadt. All construction activities taken place in Berlin announced to community via this platform (Figure 5) [8] 


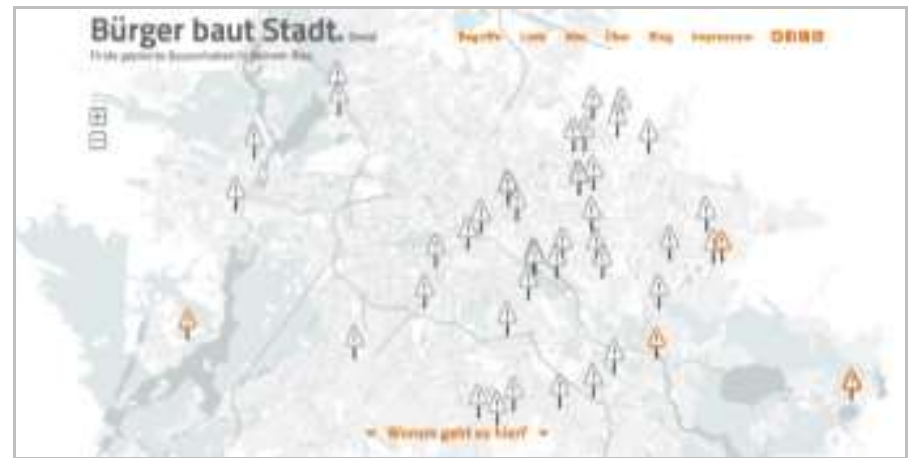

Fig. 5: An informative platform where all construction activities are announced to community [8]

- Data Collection: There is need for actual data in order to meet users' need after the announcement of urban transformation areas. Both physical values and social values are crucial in terms of data collection. Different actors like researchers, specialist who provide data, citizens take charge in collecting actual data about transformation areas. Developed countries have some advantage in terms of this issue because they have open government data. Turkey has made progress about storage and sharing of data for several years but these developments are not enough for the transformation process. Turkey 41th country in 86 countries which are evaluated by Open Data Barometer [9] On the other hand, the population of Turkey use internet and social media too much so this area has important potential. Some actions such as collecting data, determining problems and expectations of citizens should be realized via social media application (Figure 6). Moreover, this information should get by Application Programming Interfaces (API).

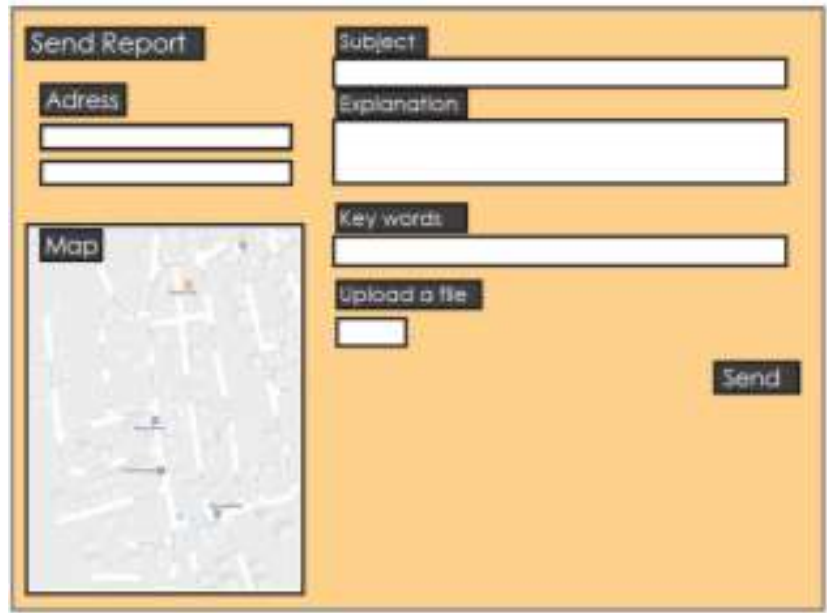

Fig. 6: A mobile application mockup that serves citizens for reporting problems and expectations about their living environment

Geographic Information Systems should be used for mapping of urban interventions and collecting, analyzing and monitoring data collected by citizens. ArcGIS which enable users to enter, store and analyze data and have the capability of transforming data to map, graphic and tables and sharing them via the internet.

- Data Visualization: Taken decisions are generally announced by officials but the greater part of the community can't access because of some reasons such as publishing format. Thus, data about transformation areas should transfer to data repository and then data expert visualizes data as more comprehensible format such as infographic, diagram and table so that citizens can understand. Quadrigram software, which is a data visualization tool and enables user to create interactive visuals by using XLS (Excel) and CSV (Comma-Separated Variables) files should be used in this phase. Visualized data should be used as a base for the decision-making.

- Decision Making: After data visualization, decision-making process for transformation area is started. The main actors of this phase are residents. After some actions such as meetings, public opinion polls, public games amongst stakeholders, design characteristics of transformation areas are decided. Some visual materials such as simulations, 3D models are prepared in accordance with demands of stakeholders and they are shared with the community. After this phase, construction process should be started.

- Construction: Some construction practices can't be realized in compatible with project drawings because of some reasons. Providing a transparent process in this phase is important in order to overcome this problem. Thus, construction process should be monitored by control team and the information about construction process should be shared with the community.

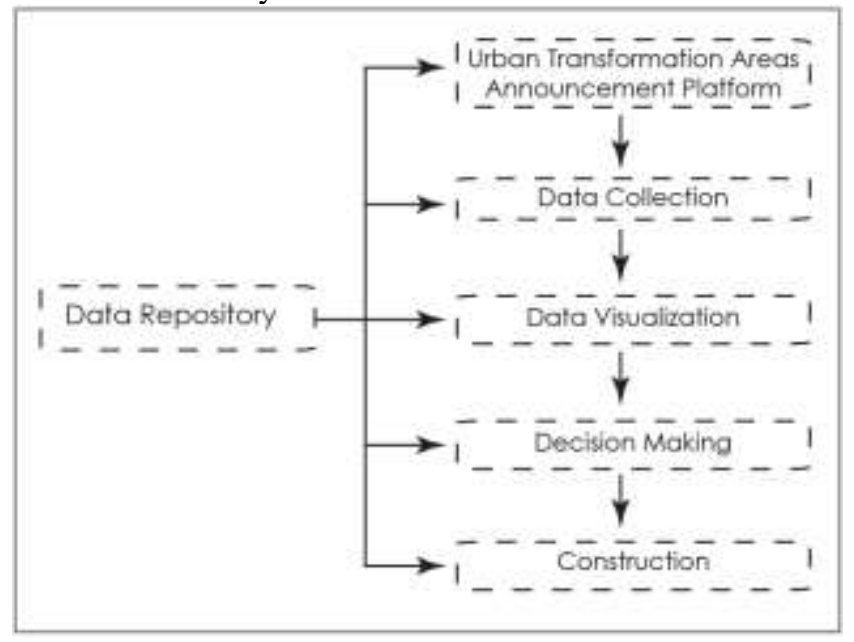

Fig. 6: The main components of proposed decision support system.

\section{CONCLUSION}

The urban interventions which have taken place for many years in Turkey damage the cultural and social values of cities. 
Most of these interventions have been realized like West Europe's social housing approach which occurred after the Second World War by considering only physical values. Transformation process should be carried out by a new approach which enables stakeholder involvement and considers cultural and natural values of the area as a key element of transformation.

Thus, this study proposes a participatory decision support system towards the transformation of areas under disaster risk in Turkey. This system includes many different actors such as residents, specialist for data collecting, local government members, Ministry's members, NGOs, design and technical team, construction firms. Accordingly, effective organization and communication atmosphere is needed so that these actors can coordinate and work in a planned way. Important actions such as data collection and share, data visualization, process management, communication amongst actors can be realized by developing a tool in accordance with information technologies.

Proposed decision support system has some basic components such as urban transformation area announcement platform, data collection, data visualization, decision making. It is possible to create an urban transformation process which considers natural and cultural values of areas and enable stakeholder involvement by putting into practice this system. The components of the system should be developed as mobile application, internet platform by using information technologies. In addition, this system should be implemented and tested on a pilot area which is under disaster risk and it should be revised in accordance with feedbacks from pilot study.

\section{REFERENCES}

[1] Resmi Gazete (Official journal), 31.05.2012, http://www.resmigazete.gov.tr, accessed at: 21.12.2016

[2] Jonathan Bright, O. I. I., \& Taha Yasseri, O. I. I. (2015). Social and Open Data Visualisation Methods and Data Source Report.

[3] www.wikiwand.com, accessed at: 02.01.2016

[4] www.dialog-mariahilferstrasse.at, accessed at: 02.01 .2016

[5] Druzdzel, M. J., \& Flynn, R. R. (1999). Decision support systems. Encyclopedia of library and information science. A. Kent. Marcel Dekker, Inc. Last Login, 10(03), 2010.

[6] Tripathi, K. P. (2011). Decision support system is a tool for making better decisions in the organization. Indian Journal of Computer Science and Engineering (IJCSE), 2(1), 112-117.

[7] Ayeni, B. (1997). The design of spatial decision support systems in urban and regional planning. Decision Support Systems in Urban Planning, 3-22.

[8] https://www.buergerbautstadt.de/, accessed at: 01.05.2016

[9] http://www.opendatabarometer.org/report/analysis/rankings.html, accessed at: 03.01 .2016 